\title{
Improvement of the bitumen extraction technology from bituminous sand deposits
}

\author{
Larysa Pedchenko ${ }^{1}$, Nazar Pedchenko ${ }^{1}$, Jerzy Kicki $^{2}$, and Mykhailo Pedchenko ${ }^{1 *}$ \\ ${ }^{1}$ Poltava National Technical Yuri Kondratyuk University, Department of Oil and Gas Exploitation \\ and Geotechnics, 24 Pershotravnevyi Ave., 36011 Poltava, Ukraine \\ ${ }^{2}$ Mineral and Energy Economy Research Institute of the Polish Academy of Sciences, Division of \\ Mineral Resource Acquisition, 7 Wybickiego St., 31-261 Krakow, Poland
}

\begin{abstract}
Today considerable experience in the development of tar sands is accumulated. However, well-known mining technologies do not cover the entire depth range of natural bitumen deposits. In addition, there are significant energy-intensive technologies and negative environmental impacts. In view of this, the purpose of this work is to improve the method of extracting natural bitumen in site for a deposit interval of $75-200 \mathrm{~m}$ and to substantiate the basic technological scheme of this method. The proposed method of extracting bitumen from poorly cemented reservoirs in the depth range of $50-400 \mathrm{~m}$ provides: creation of artificial mine working; the transfer of the rock into the water mixture composition under the action of high pressure jets of a heated mixture of water, a hydrocarbon solvent and a flotation agent; separation from the rock and concentration of bitumen in the production as a result of its heating, dissolution and flotation; selection of depleted bitum slurry from the mine working by gas lift method. The proposed method of extracting bitumen is the transfer of the rock at the site of its occurrence to the suspension condition on the excavation created by the hydraulic production method, separation and concentration of bitumen by dissolving it with a heated hydrocarbon solvent and a flotation agent (hydrocarbon reagents), and extraction in the composition of depleted rock slurry to the surface by the gas lift method. As the preliminary calculations show, the proposed method will allow the efficient extraction of bitumen and highly viscous oil from weakly cemented reservoirs in the depth range of $50-400 \mathrm{~m}$. Also, the proposed technology creates the preconditions for the development of oil sands at a depth of $75-200 \mathrm{~m}$ since there is currently no effective technology for the interval. In addition, it can significantly reduce energy costs, environmental pollution and greenhouse gas emissions.
\end{abstract}

\section{Introduction}

The depletion of traditional deposits and the rise in energy prices have led to considerable interest in exploring unconventional hydrocarbon fields. Heavy oil and natural bitumen are one of the strategic hydrocarbon reserves for oil companies around the world [1]. Their

\footnotetext{
* Corresponding author: pedchenkomm@ukr.net
} 
reserves are many times higher than those of traditional oil and gas.

Approximately 1.7 trillion barrels of crude bitumen are in the oil sands [2, 3], but it is predicted that only $19 \%$ of this total (315 billion barrels), will ultimately be recovered. A smaller volume, 174 billion barrels, could be recovered using modern technology under current and anticipated economic conditions [2]. (For comparison, crude oil reserves in Saudi Arabia are estimated at 264 billion barrels).

The development of natural bitumen reserves is being successfully implemented in Canada, the USA and other countries in the world [4].

Thus, oil sands development in Alberta has been increased from about 1 million barrels/day in 2004 to 2.4 million barrels/day in 2014. This is equivalent to an annual increase of $8 \%$.

All geological preconditions for the formation of large industrial clusters of highviscosity oil and natural bitumen are in Ukraine as well. However, targeted search and exploration work to identify them in Ukraine is not being conducted. All known deposits were discovered incidentally during oil and gas exploration $[5,6]$.

Bituminous sands contain $9-13 \%$ bitumen, $3-7 \%$ water and $80-85 \%$ rock. Small particles, preferably clay, with a diameter of less than 44 microns are from $15 \%$ to $30 \%$ of the rock. The task is to separate the bitumen not only from the sand grains, but also from clay particles of micron and submicron size.

In addition, bituminous oil has a high density $\left(0.965-1.22 \mathrm{~g} / \mathrm{cm}^{3}\right)$ and anomalous viscosity (over $10^{4} \mathrm{MPa} \cdot \mathrm{s}$ ). Sulfur and metals, especially vanadium and nickel in concentrations comparable to their content in ore deposits, are also part of it.

Thus, natural bitumen is significantly different from traditional oil in chemical composition, physicochemical properties, the degree of interaction with the host rocks and the nature of the saturation of the pore environment. Therefore, the methods and approaches used in the extraction of traditional oil cannot be directly implemented for the development of high-viscosity oil deposits and natural bitumen [5].

In this regard, a number of methods for the bitumen extraction from tar sands have been developed. A number of methods are in the process of refinement and improvement.

\section{Methods of oil sands development}

Oil sands are mainly developed in two ways: the extraction of bitumen by the quarry method and the methods of its extraction in site [7]. The choice of method depends mainly on the reservoir depth. Deposits at depths of up to $50 \mathrm{~m}$ and subject to surface mining account for about $20 \%$ of Canada's bitumen deposits. The remaining $80 \%$ of the oil sands that can be mined at the site.

A quarry method involves two major steps: the removal of the rock from the quarry and the extraction of bitumen in industrial installations. After the rock is extracted, bitumen is separated from the sand by the process of hot water extraction, patented in 1928 by Dr. Carl Clark (bitumen is separated from sand and clay particles by a combining mechanical energy, heat, and in the presence of surfactants). Currently modifications of this method are applied [8].

Pieces of petroleum sandy ore are ground and mixed with warm water containing $\mathrm{NaOH}$ to form an aqueous slurry at the mining sites. The slurry is then conditioned at elevated temperatures to help release the bitumen. Traditionally, extraction drums are used to extract bitumen at $80^{\circ} \mathrm{C}$. Recently, pipelines leading to the primary separation unit at $35-50{ }^{\circ} \mathrm{C}$ have been used to facilitate separation.

In hydraulic pipelines and drums, the pieces of rock left in the slurry are displaced and reduced in size. In drums or in hydraulic pipelines, bitumen is "released" from the grains of sand. Phase separation is enhanced by mechanical displacement and breaking pressure. At a 
temperature of $35-50{ }^{\circ} \mathrm{C}$ and the $\mathrm{pH}$ of the suspension within $8-8.5$, bitumen is separated, forming droplets that are released from the grains under stirring the suspension.

Since bitumen and water have similar densities, the flotation method is used to separate them. For this, bitumen is gradually aerated at a rate of about $30 \%$ by volume of gas to the mixture volume. However, it is very difficult to organize the supply of the optimum amount of air for quality aeration and to avoid excessive air supply [7].

In [9] it was shown that the aeration stage is the most critical and this has the effect of bitumen loss.

Thus, during conditioning, the liquid suspension is aerated and ideally the bitumen is separated from the sand, being attached and distributed to air bubbles. The bituminous foam collected in the gravity separation vessel contains about $10 \%$ of solids and $30 \%$ of water. The foam air bubbles are easily removed by heating or gravity drainage, but the viscous bitumen is not easily cleared of small clay particles and drops of emulsified water. Dilution of bitumen with a solvent reduces its viscosity and density and accelerates the settle of denser solids. However, emulsified droplets of water and clay particles have tiny diameters, so they settle very slowly $[10,11]$.

The process is carried out using inclined plates of sedimentation tanks, cyclones and centrifuges. For this operation, Syncrude and Suncor use a light fraction of oil (mainly hexane) as the solvent for foaming. When the solvent is used in a sufficiently high amount, the bitumen asphaltene is partially precipitated. This results in the formation of composite aggregates that catch water and solids from diluted bitumen foam. This method significantly improves the gravitational separation, thereby eliminating the need for cyclones or centrifuges.

The successful application of water-based technologies for the extraction of bitumen from the Athabasca oil sands lies in the key fact that the sand in the oil sands is hydrophilic. Also, it is believed that a thin layer of water surrounds the individual grains of sand (about $10 \mathrm{~nm}$ thick), separating them from bitumen [12]. The most characteristic feature of the Alberta oil sands is that the grains are moist or hydrophilic. This hydrophilic tendency of the sands is successful because the process of extracting bitumen with hot water would not work if the grains were not moistened.

It is assumed that the water film is stabilized by electrostatic forces resulting from the formation of a double electric layer at the boundary of the phase separation of "oil - water" and "water - sand" [13 - 16].

Quartz sand absorbs most of the bitumen and water mixture, forming a continuous phase. The water film separates bitumen from sandy and clay surfaces.

Thus, the removal of bitumen from the oil sands using the processes of water-based extraction includes the following steps:

- grinding of rock that occurs in bunkers or hydraulic pipelines in the process of heating its surface and gradual erosion;

- separation of bitumen from sand grains. (The speed of this step depends on the balance between the forces of bitumen separation from the sand grains and the force of attraction (sticking) of the bitumen to these grains.) The processes of this stage are affected by the rate of heat transfer, mechanical mixing, chemical additives and interfacial properties;

- the bitumen droplet released from the sand is attached to the air bubble. Depending on the process temperature, the bitumen either attaches to the air bubble at a low temperature process $\left(<35^{\circ} \mathrm{C}\right)$ or absorbs the bubble at a "hot" $\left(75-80^{\circ} \mathrm{C}\right)$ or a «warm» (about $45^{\circ} \mathrm{C}$ ) processes. As a result of aeration, the bitumen floats to the top of the gravity separation vessel. As a result, a layer of bitumen foam is formed.

For any production method, the extracted bitumen for quality improvement is subjected to primary processing for synthetic oil. In this case, residual of the rock (mainly clay 
fraction) and water are also removed from the bitumen. (Before distillation, the diluted bitumen product typically contains approximately $2 \%$ of water and $0.5 \%$ of fine solids.)

This processing is similar to ordinary crude oil treatment using cracking and hydrotreating processes. The synthetic crude oil is then sent to an oil refinery for further physical and chemical processing.

Unfortunately, the quarrying method cannot be used for deeper tar sands. In this case, in-situ well production technologies are applied. In this case, methods that minimize their viscosity are the most rational [17].

Among such methods, thermal and thermochemical occupy a special place. These include different combinations of steam or solvent injection through horizontal or vertical wells. Currently, two main types of in-site methods are developed and widely implemented: Cyclic Steam Stimulation (CSS) and Steam-Assisted Gravity Drainage (SAGD) [18].

Both methods include the injection of hot steam into a reservoir for heating oil sands in order to reduce the viscosity of the bitumen and to stimulate its production.

The CSS method was the first to be used in the production of bitumen in site. It includes the injection of water vapor into the well at a temperature of $250{ }^{\circ} \mathrm{C}$ to $400{ }^{\circ} \mathrm{C}$. Water vapor advancing the layer heats the bitumen, reducing its viscosity. The wells are allowed to settle for several days or weeks and then the hot oil mixed with condensed water is pumped out for weeks or months. Then the method is repeated. However, in addition to the high cost of pumping water vapor, the CSS method generally results in bitumen extraction not exceeding $20-25 \%$.

Another in-site method (currently most widely used) is Steam-Assisted Gravity Drainage. The method includes the drilling of two horizontal wells - one at the bottom of the formation and the other five meters above it. Water vapor is injected into the upper well, melting the bitumen, which then flows into the lower well.

The degree of water conversion to steam is about $75 \%$, i.e. $1 \mathrm{~kg}$ of feed water generates $0.75 \mathrm{~kg}$ of steam, and $0.25 \mathrm{~kg}$ remains in the liquid form [19].

The process of steam gravity begins with the stage of preheating, during which (several months) the steam is circulated in both wells. However, due to the conductive heat transfer, the zone of the reservoir between the extraction and injection wells is heated, the bitumen viscosity in this zone is reduced and thus the hydrodynamic connection between the wells is provided. At the main stage of extraction, steam is already pumped into the injection well.

The resulting liquid oil mixed with condensed water vapor is pumped to the surface. The level of bitumen extraction by the SAGD method reaches $40-60 \%$. However, this method is most effective for the extraction of oil sands located at a depth of more than $200 \mathrm{~m}$ [20].

The above methods have many problems related to the level of costs and the negative impact on the environment. For example, the use of large amounts of water vapor requires high energy consumption and the use (and placement) of large amounts of water. Currently, the extraction and processing of tar sands requires several barrels of water per barrel of oil obtained [21].

Open field development and further processing results in significant sand volumes that is not fully cleared. It requires further processing before being returned to the environment. In addition, the use of large quantities of caustic soda for extraction by the quarry method improves the stability of fine clay particles in waste, the removal of which is a major problem of the influence on the environmental.

Calculations show that energy consumption to increase the temperature of 1 ton of oil sand by $1{ }^{\circ} \mathrm{C}$ is about $5 \mathrm{MJ}$. Such an energy-intensive process inevitably releases greenhouse gases that pose a threat to the environment. Therefore, for the development of natural bitumen deposits with the achievement of acceptable values of extraction coefficients, new methods are needed that are superior to the efficiency of traditional steam-boiling technologies.

Solvent extraction is one possible alternative. Here, the introduction of thermal energy 
at the beginning of the extraction process can be minimized (the process can be carried out even at ambient temperature) by adding solvents that reduce the viscosity of the bitumen.

In this regard, methods of the bitumen extraction by the solvent (eg, VAPEX, N-Solv) are being developed.

Thus, in the VAPEX - VAPor EXtraction method (using solvents in a vaporous state) a mixture of solvents (propane, butane, oil and methane) is pumped into the reservoir in the form of steam into the upper horizontal well (Fig. 1). The solvent is mixed with bitumen to reduce its viscosity.

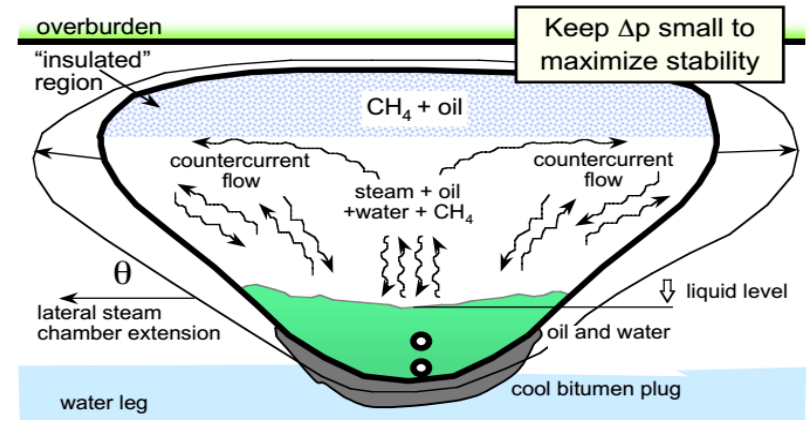

Fig. 1. Basic elements of SAGD (\& VAPEX).

The extraction process is carried out through the lower horizontal well. The process uses no water and produces no $\mathrm{CO}_{2}$. But the project has not yet found widespread implementation as a number of important technical issues have not been resolved (the process of dissolution is very slow).

New technology of N-Solv (Fig. 2), includes pumping into the reservoir of solvent (propane) heated to a temperature of $\sim 50{ }^{\circ} \mathrm{C}$. Propane dissolves bitumen, its heaviest components remain underground. Lighter oil and solvent, which is able to restore, are lifted to the surface. In addition, the mass is less viscous than in the traditional underground method, so it can be immediately transported by pipeline.

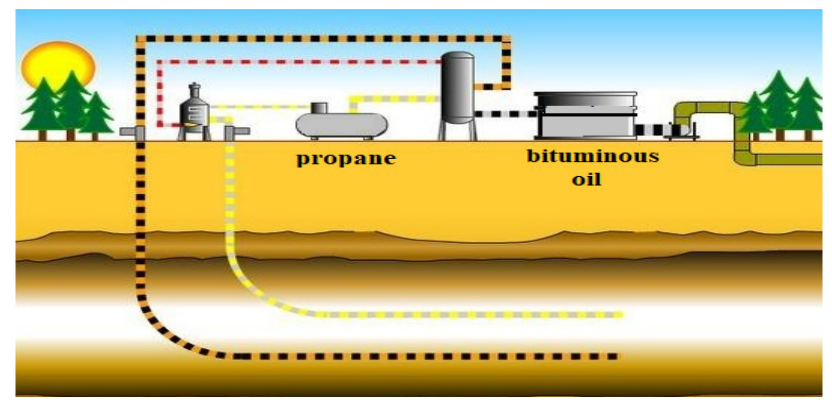

Fig. 2. Technology of oil extraction from tar sands (N-Solv technology).

Moreover, the improvement of the N-solv technology itself by heating the solvent, as well as purifying it from methane admixture made it possible to significantly increase the efficiency of the process. (It was found that the methane presence in the formation significantly worsens the process of heat exchange at the interface of solvent - bitumen).

As a result, greenhouse gas emissions are reduced by $80 \%$ compared to traditional methods of production. In addition, the heavy admixtures present in bitumen - such as sulfur, asphaltenes, heavy metals and the heaviest hydrocarbon fractions - remain underground. 
However, known methods that include the injection of water vapor or hydrocarbon solvents have a significant disadvantage associated with the rock heterogeneity of the productive layers. This inevitably leads to their breaking in the production wells and the need to apply flow diversion technologies (blocking gels, sediment-forming compositions).

Because of this, most horizontal sections of SAGD wells are laid at a depth of more than $200 \mathrm{~m}$ (due to the danger of the agent breaking into the surface). The paper [20] analyzes 28 SAGD wells. They are drilled in the range of $212-425 \mathrm{~m}$, at an average of $303 \mathrm{~m}$.

As the lower boundary of the quarry development is $75 \mathrm{~m}$ depth, there is a considerable interval of natural bitumen bedding (at least of $125 \mathrm{~m}$ thickness (in the range of $75-200 \mathrm{~m}$ ) for which there is no acceptable extraction technology.

Thus, today there is a need for efficient, safe and economical ways of removing bitumen from tar sands. In addition, an important task is to develop an effective method for the specified interval of tar sands bedding.

\section{Substantiation of technology parameters}

An analysis of the accumulated experience in the development of tar sands shows that one of the ways in-site technology development (for this interval) could be the technology proposed by the authors. It would allow processes to be carried out directly in the area of the bituminous rock occurrence. The processes are similar to those occurring in aboveground technological equipments (bituminous sand processing) by the Clark method [8].

Moreover, the area of implementation of these processes, considering the need to reduce energy consumption and environmental impact, should be local, controlled and as isolated as possible.

The latter condition, taking into account the properties of the bituminous rock, can be fulfilled provided that the pressure in the limited working area is not at the level of formation pressure.

These requirements, in our opinion, can be fulfilled provided the consistent implementation by the technology of the following operations:

- formation in the productive layer of mine working, which will be an area for geotechnological processes, according to the Clark method [8];

- bringing into the mine working of the necessary amount of heat and reagents to reduce the viscosity of bitumen and its separation from the rock;

- formation of conditions for efficient bitumen extraction and its recovery in the most concentrated form.

In addition, the technology must have minimal impact on the environment, provide maximum heat recovery, have a minimum period from the beginning of the project to the receipt of products and output to the design capacity.

Analysis of the currently known technological solutions has shown that the above requirements can correspond the technology developed on the basis of elements of well hydraulic mining technology [22].

This technology includes uncovering the deposit with a well, the rock's breaching at the place of its occurrence with the help of a jet stream, the transfer of the rock into the hydraulic mixture composition and extraction to the surface [22].

The mechanism of hydraulic rocks fracturing is a complex process caused by the simultaneous action of a number of factors. These include normal and tangential stresses when the jet influences on the massif, dynamic shock action, filtration pressure, abrasive action, etc. [23].

An added advantage of the technology is that it allows mining of disconnected ore bodies in flooded face under high water inflows, as well as under water basins and offshore. 
However, a rapid decay of the jet energy occurs in the conditions of flooded face. This requires the use of hosepipes or telescopic monitors that lengthen as the face advances. As a result, the extraction of the rock mass and the unit construction are complicated, as well as the risk of the roof collapse and clogging of equipment. Therefore, this technology requires improvement and adaptation to the features of the tar sands deposits development. Significant susceptibility to bituminous sand disintegration (especially after reducing the bitumen viscosity as a result of heating or solvent action) is a positive factor of this method. Taking into account the above requirements for bitumen and high-viscosity oil extraction technology at the site of their bedding, as well as the features (and disadvantages) of the technology of well hydraulic mining of the minerals in works [24, 25], a method (Fig. 3) is proposed, which includes:

- uncovering of the productive layer with horizontal well 8 heated by working fluid water with surfactants;

- transfer of the rock (from the bottom of the well) to the slurry as a result of the action of high-pressure working fluid streams (stream III) $(5-20 \mathrm{MPa})$ at a temperature above $100{ }^{\circ} \mathrm{C}$ (stream III). Moreover, the rods of hydromonitors 7 with nozzles in the working position occupy perpendicular position to the axis of the well. In the process, they rotate around the well axis and gradually move along in the direction of contact with the fracture front. Mine working is gradually formed, being developed in the direction of the wellhead;

- enhancement of the destructive action of the working fluid jets due to the abrasive action of the rock particles 2, which are captured by the hydromonitore jets 7 together with part of the pulp in the interval from the nozzle cut to the front of destruction;

- introduction into the mine working of thermal energy with the working fluid flow to reduce the bitumen viscosity;

- the gravitational separation from the formed pulp of the main part of the rock 2 (except for the clay fraction) at some distance beyond the hydromonitors 7 (where turbulent mixing is extinguished). As a result, the pulp is enriched with bitumen and pushed back to the mine working arch;

- withdrawal from the mine working of bitumen-enriched pulp (stream $I I$ ) through the slurry tank 5 , located in the arch area of the mine working to the separator 12 ;

- separation of the solid phase remainder from the pulp in the separator 12 (stream $I$ );

- the selection of the bitumen concentrate (stream $I V$ ) and sending it for further processing.

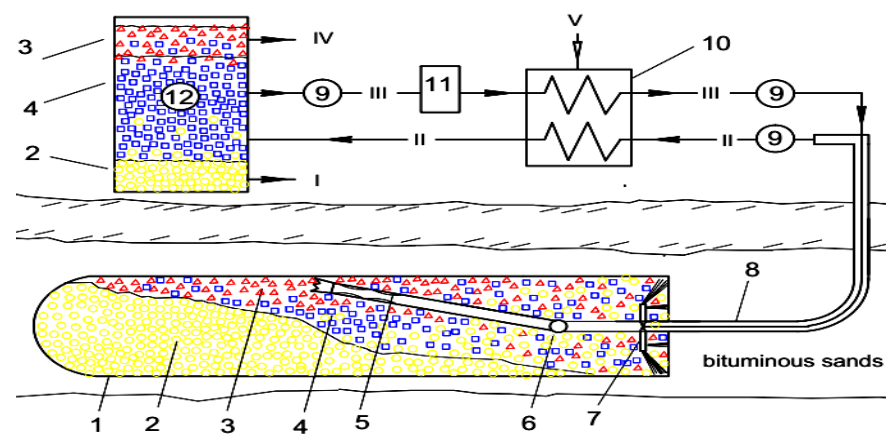

Fig. 3. Scheme of the bitumen extraction method from the tar sands deposits: 1 - production; 2 sediment of sand; 3 - bitumen-enriched pulp; 4 - water with a clay fraction; 5 - a shank with a chisel and a pulp gathering; 6 - the hinge; 7 - hydromonitor device; 8 -well; 9 - pump; 10 - block of heating; 11 - a block of partial separation of the solid phase; 12 - separator; streams: I - sand settling; II - bitumen-enriched pulp; III - clay solution; IV - bitumen; V - a coolant. 
It is also assumed that outside the hydraulic system where the pressure corresponds to a formation pressure (reservoir), the level of the fluid superheating in the fracture zone will be sufficient to boil it. The formation of water vapor bubbles in the rock pores will increase the process of its disintegration. Then, in the resulting water mixture, the bitumen drops are attached to the bubbles. Similarly to the processes carried out in the extraction plants, the process of bitumen flotation will take place in the mine working to its arch.

However, the technology proposed in $[24,25]$ is based on thermal processes of bitumen extraction and therefore cannot be perfect in terms of energy efficiency, environmental impact caused by $\mathrm{CO}_{2}$ emissions. Therefore, there are reserves for its improvement and increasing competitiveness.

Heating (even in the localized zone) of the productive layer, based on the bitumen low content, heat capacity and thermal conductivity of the rock, without the prospect of heat recovery is unjustified.

It is known that a positive result can be achieved by using solvent for bitumen to reduce the viscosity. (The positive experience of moderate heating (e.g. up to $50{ }^{\circ} \mathrm{C}$, N-Solv method) should also be used). It is also expedient to use the liquid solvent as part of the working fluid of the hydromonitors when introducing it into mine working.

In addition, instead of the bitumen flotation with water vapor bubbles, it should be provided to introduce into the mine working a flotation agent which, under thermobaric conditions in the mine working, is in a gaseous state and in the supply line it is in a liquid state. (Therefore, it is fed into the mine working as a working fluid component of hydromonitors).

Also, to maximize bitumen extraction and reduce solvent losses, the following should be considered.

It is estimated that about $70-80 \%$ of the rock (mainly sand), based on the composition of bituminous sand, will separate as a result of gravitational deposition from the pulp in the mine working. As a result, the mine working approximately $4 / 5$ of the cross section will be filled with sediment. Its porosity will be about $30 \%$. On this basis, ideally the process should be organized in such a way that the pore space of the sediment is filled with a slurry of water and clay fraction of the rock. In this case, all the bitumen, together with the flotation agent, will be displaced from the sludge to the mine working arch.

After taking into account (and agreeing) the above positions, a method (geotechnology) and a schematic diagram (see Fig. 4) of "cold" hydraulic mining of bitumen in-site from deposits located at a depth of 50 to $400 \mathrm{~m}$ are proposed.

The method provides:

- uncovering the reservoir with horizontal wells;

- transfer of the rock (starting from the face) to the slurry as a result of the action of working fluid jets (stream VIII) of high pressure $(5-20 \mathrm{MPa})$ at a temperature of about $50{ }^{\circ} \mathrm{C}$. Moreover, the rods of hydraulic monitors 7 with nozzles in the working position which are perpendicular to the well axis position. In the process of operation, they rotate around the well axis and gradually move in the direction of contact with the fracture front. The mine working (mining) is gradually formed and developed in the direction of the wellhead. Disintegration of the productive layer rock is carried out by high-pressure working fluid jets, which include water, flotation agent and bitumen solvent. In this case, the flotation agent is in a condensed state under the thermobaric conditions of the flow line of the working fluid and until the nozzles cut of hydromonitors, and in the mine working it evaporates. After that, its part in the form of bubbles is attached to the bitumen drops and the rest is accumulated in the mine working arch;

- enhancement of the destructive action of the working fluid jets due to the abrasive action of the particles of the rock 2, which are captured by the hydromonitor jets 7 together with part of the pulp in the interval from the nozzle cut to the front of destruction; 
- the separation of natural bitumen from the rock occurs as a result of reducing its viscosity under the action of solvent;

- at some distance behind the hydromonitors 7 (where turbulent mixing goes off) the gravitational separation of the hydraulic mixture into the sediment layer (rocks 2 and water in the pores), the gas cap 3 of the flotation agent vapor in the mine working arch, and the target product layer between them - hydraulic mixture enriched with the bitumen 4 (bitumen, solvent, water, clay fraction of rock and flotation agent);

- selection from the mine working (stream $I$ ) of hydraulic mixture enriched with bitumen 4 is carried out by gas lift method due to the excess pressure formed by the working fluid (stream VIII) and the flotation agent in the gas cap 3;

- the selection of the target product (stream $I$ ) to the separator 12 is carried out through the intake device 5 , which in the working position floats to the pulp concentrate area and its end, to capture gas for forming the gas lift effect, is located on the border of the pulp - gas cap. In this case, the intensity of the enriched pulp selection will be regulated by the flow rate of the hydromonitors working fluid and its composition;

- separation in the separator 12 of the hydraulic mixture selected from the mine working in the working fluid (stream $I I I$ ), which under pressure is fed to the hydraulic monitors 7 , a bitumen mixture, flotation agent and solvent (stream $I V$ ) and rock (stream $I I$ ).

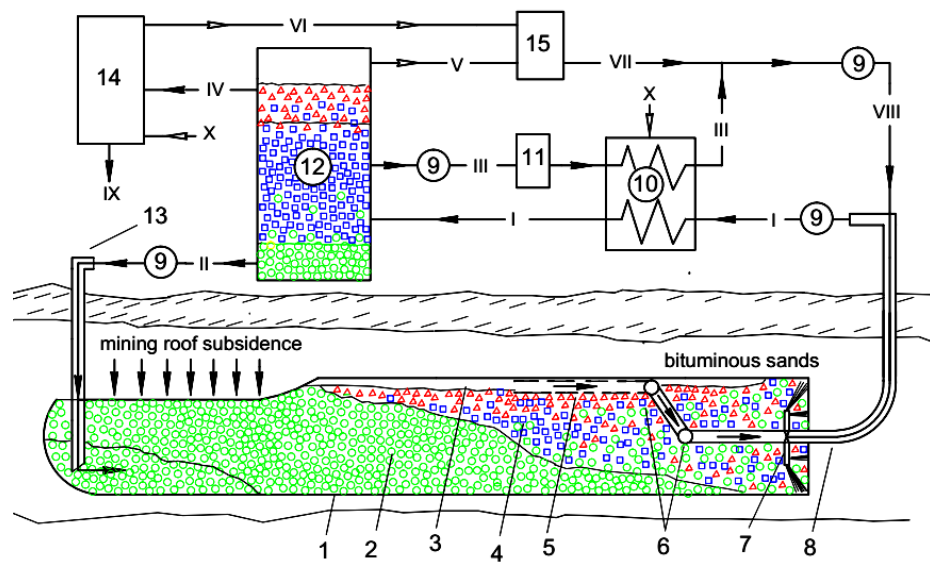

Fig. 4. Schematic diagram of an improved method of extracting bitumen from tar sands: 1 - mine working; 2 - rock sediment; 3 - gas cap; 4 - water mixture, enriched with bitumen; 5 - intake device; 6 - swivel connection; 7 - hydromonitors; 8 - horizontal section of the well; 9 - pump; 10 - the heater; 11 - a filter; 12 - separator; 13 - injection well; 14 - evaporation column; 15 - the liquefaction unit; flows: I - mixture of bitumen, solvent, water, clay fraction of rock and flotation agent; II - rock; III - water; IV - a mixture of bitumen, solvent and flotation agent; V - a gaseous flotation agent; VI - gaseous solvent and flotation agent; VII - liquefied solvent and flotation agent; VIII - a mixture of water, solvent and flotation agent; IX - bitumen; X - supply of thermal energy.

It is proposed to use a propane-based gas mixture as a flotation agent. Moreover, the ratio of these components in the mixture will depend on the technological parameters of the particular object of mining (depth of bedding and temperature in the mine working).

A wide fraction of light hydrocarbons obtained from the destruction of the produced bitumen in the process of its preliminary preparation is proposed to be used as a solvent. Its component composition will also be determined by the specific conditions of the mining object.

The mixture of bitumen, solvent and flotation agent (stream $I V$ ) in the evaporator 14 is divided into bitumen (stream $I X$ ), flotation agent and solvent vapours (stream $V I$ ). The 
flotation agent (stream $V$ ), separated in the separator 12, and mixture vapors of flotation agent and solvent from the evaporation column 14 (stream $V I$ ) are liquefied in the block 15 . The water from the separator 12 (stream $I I I$ ), if necessary, additionally purified from the clay admixtures in the filter 11 , heated to a temperature of $50-60{ }^{\circ} \mathrm{C}$ and connected with the flow of liquefied solvent and flotation agent (stream VIII) and high pressure pumps 9 , is fed to the hydromonitors (as a working fluid). Water, flotation agent and solvent to the hydromonitors (given the small diameter of the pipeline, high pressure and flow rate) come in as an enough dispersed and homogeneous mixture.

The sediment from the separator 12 and other waste through the injection well 13 in the form of flow $I I$ are pumped into the lower part of the spent mine working (production) interval (to prevent a breakthrough into the mining area).

One of the parameters that is proposed to take into account when choosing the diameter of the formed mine working is its mechanical resistance to fracturing. The best option will be when in the interval of the working area the arch will be stable. But at some distance, the mine working will gradually deformed, while pushing pulp and gas cap enriched with bitumen to the working zone.

The pressure in the mine working (production) 1 will be insignificant and will exceed the hydrostatic pressure only by the amount necessary for the organization of the gas lift process of the hydraulic mixture. Therefore, the pulp breakthrough to the surface is excluded. Therefore, there will be no limitations on the characteristics of the rock in the productive layer roof.

Based on the processes that will take place in the mine working, the bitumen extraction coefficient by this technology can compete with the coefficient of the quarry method. The method will allow easy extraction of bitumen (highly viscous oil) at the site at any depth of bedding, starting from the minimum one.

The profitability of in-situ oil sands development technologies is primarily determined by the bitumen extraction coefficient and specific energy consumption. However, with the recent fall in oil prices, the development of oil sands has faced difficulties. In this regard, the presented technology has a number of advantages. It will be the most energy efficient because it does not provide a period of long pre-heating of the rock. In addition, thermal energy is introduced directly into the zone of the rock destruction. As a result, energy losses to the surrounding rock will be minimal. It is assumed that the bitumen extraction coefficient is at the level of the quarry method.

\section{Conclusions}

A method of extracting bitumen from weakly cemented reservoirs is proposed and scientifically substantiated, which includes: formation of artificial mine working (production); the transfer of the rock into the composition of the water mixture under the action of high pressure jets of a heated mixture of water, a hydrocarbon solvent and a flotation agent; separation of bitumen from the rock and its concentration in the mine working as a result of its heating, dissolution and flotation; selection from the mine working (production) of suspension depleted in the rock by the gas lift method.

The proposed method allows the extraction of bitumen from weakly cemented reservoirs at the place of occurrence for a depth interval of $75-400 \mathrm{~m}$.

The proposed method does not require preliminary drainage of the site, and therefore shortens the start of mining.

The pressure in the mine working will be around to the hydrostatic one, so the pulp breakthrough to the surface is excluded. There will also be no limitations on the characteristics of the rock in the roof of the productive formation. 
The duration of preparatory operations will be insignificant. The selection of products will begin almost immediately after the inflow of the working fluid to the hydraulic monitors.

Authors express their gratitude for the help and consultation during work performance to the general director of the firm "Nadraspetstekhnolohii" Ph.D., Professor Ivan Zezekalo.

\section{References}

1. Bondarenko, V., Kovalevs'ka, I., \& Ganushevych, K. (2014). Progressive technologies of coal, coalbed methane, and ores mining. London, United Kingdom: CRC Press, Taylor \& Francis Group. https://doi.org/10.1201/b17547

2. Nosić, A., Karasalihović Sedlar, D., \& Jukić, L. (2017). Oil and gas futures and options market. Rudarsko Geolosko Naftni Zbornik, 32(4), 45-54. https://doi.org/10.17794/rgn.2017.4.5

3. Kraemer, D., Bajpayee, A., Muto, A., Berube, V., \& Chiesa, M. (2009). Solar assisted method for recovery of bitumen from oil sand. Applied Energy, 86(9), 1437-1441. https://doi.org/10.1016/j.apenergy.2008.12.003

4. Lukin, O.Y. (2008). Vuhlevodnevyi potentsial nadr Ukrainy ta osnovni napriamky yoho osvoiennia. Visnyk Natsionalnoi Akademii Nauk Ukrainy, (4), 56-67.

5. Stebel'ska, H.Y. (2015). Heolohichni umovy rozvidky ta rozrobky pokladiv vysokoviazkykh naft ta pryrodnykh bitumiv. Visnyk Kharkivskoho Natsionalnoho Universytetu, (1157), 53-57.

6. Bondarenko, V., Svietkina, O., \& Sai, K. (2017). Study of the formation mechanism of gas hydrates of methane in the presence of surface-active substances. Eastern-European Journal of Enterprise Technologies, 5(6 (89)), 48-55. https://doi.org/10.15587/1729-4061.2017.112313

7. Masliyah, J., Zhou, Z. J., Xu, Z., Czarnecki, J., \& Hamza, H. (2008). Understanding Water-Based Bitumen Extraction from Athabasca Oil Sands. The Canadian Journal of Chemical Engineering, 82(4), 628-654. https://doi.org/10.1002/cjce.5450820403

8. Kasperski, K.L. (2001). Review of research on aqueous extraction of bitumen from mined oil sands. https://doi.org/10.4095/305295

9. Liu, J., Xu, Z., \& Masliyah, J. (2005). Processability of Oil Sand Ores in Alberta. Energy Fuels, 19(5), 2056-2063. https://doi.org/10.1021/ef050091r

10. Romanova, U.G., Valinasab, M., Stasiuk, E.N., Yarranton, H.W., Schramm, L.L., \& Shelfantook, W.E. (2006). The Effect of Oil Sands Bitumen Extraction Conditions on Froth Treatment Performance. Journal of Canadian Petroleum Technology, 45(9), 36-45. https://doi.org/10.2118/06-09-03

11. Schramm, L.L., Stasiuk, E.N., Yarranton, H., Maini, B.B., \& Shelfantook, B. (2003). Temperature Effects in the Conditioning and Flotation of Bitumen From Oil Sands in Terms of Oil Recovery and Physical Properties. Journal of Canadian Petroleum Technology, 42(8), 55-61. https://doi.org/10.2118/03-08-05

12. Czarnecki, J., Radoev, B., Schramm, L.L., \& Slavchev, R. (2005). On the nature of Athabasca Oil Sands. Advances in Colloid and Interface Science, 114-115 (53-60). https://doi.org/10.1016/j.cis.2004.09.009

13. Czarnecki, J., \& Moran, K. (2005). On the Stabilization Mechanism of Water-In-Oil Emulsions in Petroleum Systems. Energy Fuels, 19(5), 2074-2079. https://doi.org/10.1021/ef0501400

14. Czarnecki, J., Moran, K., \& Yang, X. (2008). On the "Rag Layer" and Diluted Bitumen Froth Dewatering. The Canadian Journal of Chemical Engineering, 85(5), 748-755. https://doi.org/10.1002/cjce.5450850520

15. Taylor, S. (2018). Interfacial Chemistry in Steam-Based Thermal Recovery of Oil Sands Bitumen with Emphasis on Steam-Assisted Gravity Drainage and the Role of Chemical Additives. Colloids and Interfaces, 2(2), 16. https://doi.org/10.3390/colloids2020016 
16. Drelich, J. (2008). Wetting phenomena in oil sand systems and their impact on the water-based bitumen extraction process. Mining, Metallurgy \& Exploration, (25), 1-12. https://doi.org/10.1007/BF03403379

17. Shah, A., Fishwick, R., Wood, J., Leeke, G., Rigby, S., \& Greaves, M. (2010). A review of novel techniques for heavy oil and bitumen extraction and upgrading. Energy \& Environmental Science, 3(6), 700-714. https://doi.org/10.1039/b918960b

18. Lazzaroni, E. F., Elsholkami, M., Arbiv, I., Martelli, E., Elkamel, A., \& Fowler, M. (2016). Energy infrastructure modeling for the oil sands industry: Current situation. Applied Energy, (181), 435-445. https://doi.org/10.1016/j.apenergy.2016.08.072

19. Hofmann, H., Babadagli, T., \& Zimmermann, G. (2014). Hot water generation for oil sands processing from enhanced geothermal system: process simulation for different hydraulic $\begin{array}{llll}\text { fracturing } & \text { scenarios. } & \text { Applied } & \text { Energy, }\end{array}$ https://doi.org/10.1016/j.apenergy.2013.07.060

20. Rui, Z., Wang, X., Zhang, Z., Lu, J., Chen, G., Zhou, X., \& Patil S. (2018). A realistic and integrated model for evaluating oil sands development with Steam Assisted Gravity Drainage $\begin{array}{lllll}\text { technology in } \quad \text { Canada. } & \text { Applied }\end{array}$ https://doi.org/10.1016/j.apenergy.2018.01.015

21. Allen, E.W. (2008). Process water treatment in Canada's oil sands industry: I. Target pollutants and treatment objectives. Journal of Environmental Engineering and Science, 7(2), 123-138. https://doi.org/10.1139/S07-038

22. Bondarchuk, I.B., \& Shenderova, I.V. (2015). Classification of hydraulic borehole mining technological processes during pay zone development. IOP Conference Series: Earth and Environmental Science, (24), 012004. https://doi.org/10.1088/1755-1315/24/1/012004

23. Rehbinder, G. (1980). A Theory about Cutting Rock with Water Jet. Rock Mechanics, 12(3-4), 247-257. http://dx.doi.org/10.1007/bf01251028

24. Pedchenko, L., Pedchenko, N., Manhura, A., \& Pedchenko, M. (2019). Development of natural bitumen (bituminous sands) deposits based on the borehole hydro-extraction technology. E3S Web of Conference, (123), 301036 https://doi.org/10.1051/e3sconf /201912301036

25. Pedchenko, M., \& Pedchenko, L. (2018). Expanding of spheres the application of borehole hydroproduction technology to develop deposits of non-traditional hydrocarbons. E3S Web of Conference, (60), 00018. https://doi.org/10.1051/e3sconf/20186000018 